\title{
Energy Recovery from Contaminated Biomass
}

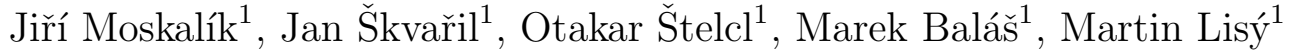 \\ ${ }^{1}$ Brno University of Technology, Faculty of Mechanical Engineering, Energy Institute, Technická 2896/2, 616 69 Brno, \\ Czech Republic
}

Correspondence to: ymoska03@stud.fme.vutbr.cz

\begin{abstract}
This study focuses on thermal gasification methods of contaminated biomass in an atmospheric fluidized bed, especially biomass contaminated by undesirable substances in its primary use. For the experiments, chipboard waste was chosen as a representative sample of contaminated biomass. In the experiments, samples of gas and tar were taken for a better description of the process of gasifying chipboard waste. Gas and tar samples also provide information about the properties of the gas that is produced.
\end{abstract}

Keywords: gasification in a fluidized bed, contaminated biomass, thermal disposal of waste.

\section{Introduction}

The growth in energy consumption has led to interest in non-conventional fossil fuels. Biomass is an option for reducing the use of primary energy sources. An advantage of biomass is that it can be transformed directly into liquid and gaseous fuels [1]. If these fuels achieve certain quality parameters, e.g. purity or satisfactory heat value, they can be used in a more suitable way. In recent times, there have been considerable advances in recovering energy from biomass, even in large-scale energy production. A well-known example has been the interventions made by the state in support of feed-in tariffs for power coming from renewable sources. A situation developed when, due to the major impact on the market this type of fuel became "scarce goods", particularly for larger consumers. Then consumers begin to look around for some other type of fuel. These criteria for biomass production are also met by certain non-toxic wastes that can summarily be referred to as contaminated biomass. Contaminated biomass includes materials such as wastes from agricultural production, and wastes from the furniture industry. Energy recovery from contaminated biomass can be regarded from two angles, one of which focuses on energy production, while the other focuses above all on waste disposal. Legislative problems of gasification of contaminated biomass are beyond the scope of this paper, but would form a topic for a separate paper by a different kind of specialist.

\section{Basic types of contaminated biomass}

The main hindrance to recovering energy from contaminated biomass is its elevated content of unde- sirable substances. Biomass is usually contaminated in its primary, non-energy use. Contaminants may vary significantly, according to the primary use and the origin of the biomass. Basically, contaminated biomass can be classified into a small number of basic groups, as follows:

- agricultural production wastes [2]

- construction industry wastes

- furniture industry wastes

- sludge from waste water treatment plants

- wastes from paper production and cellulose processing

- wastes from the textile industry - biological components and plant residues used in textile production (flax, cotton, hemp, etc.)

Each group has its specific features, according to the type of substances the biomass has been exposed to, or treated with, for its primary use. While wastes from agricultural production tend to have elevated levels of nitrates, construction industry wastes have frequently been treated with protective agents, bonding primers, paints, etc. [3].

\section{Experimental fuel}

Since the material is readily availability, our study focuses on wastes from furniture manufacture. These wastes include materials contaminated by being processed with chemicals (e.g. bonds and binders, glues and adhesives, lacquers, and also biocidal products).

A typical representative of wastes from furniture manufacture is waste chipboard. This waste contains a whole gamut of additives to boost the resistance of the wood. Waste chipboard has a suitable consistency and is quite widely available. Chipboard was chosen for experiments using the Biofluid 100 gasifier. For operating reasons, the chipboard has to be 
crushed to be able to be fed way of screw conveyor into the gasifier.

An analysis of the elemental composition and the basic properties of the experimental fuel was carried out by an accredited laboratory. The results of the analysis are summarized in the following tables.

\section{Analysis of the experimental fuel sample}

There are only very small quantities of fluorides in crushed chipboard $(284[\mathrm{mg} / \mathrm{kg}]$ in dry matter, which corresponds to only $0.000284 \%$ ). Fluorides, together with chlorine, are problematic halogen compounds in the fuel sample. Halogens are present here in relatively small quantities; however, what also matters is the compounds in which they are chemically bound. At relatively low gasification temperatures, some compounds may fail to decompose completely. Undesirable compounds may only undergo a transformation, giving rise to substances harmful to the living environment $[5,6]$. Compounds of chlorine are likely to be the most troublesome substances in this respect. In a fluidized bed, however, undesirable pro- duction of harmful substances is expected to be minimized owing to the large contact area [2].

The wood and chipboard used in furniture production are very often treated with biocidal products. These products are used to prolong the life of the material, to prevent the development of mould and material degradation. Biocidal products often contain chlorine, and their molecular structure often takes after the molecular structure of dioxins or furans. Furans and dioxins rank among the most toxic substances of all [7].

\section{Energy properties of chipboard}

From the energy point of view, the heat value is probably the most essential property of fuels. Chipboard consists mainly of pieces of wood that have been treated to meet the requirements for furnituremaking (e.g. low humidity). All kinds of glues and resins are considerable components of chipboard which also, in most cases, have good heat values. The experimentally verified heat value of chipboard is relatively high (see table 2 ).

Table 1: Results of the initial ultimate analysis of the experimental fuel $[3,4]$

\begin{tabular}{|l|c|c|c|}
\hline Anneal & $\begin{array}{c}\text { Obtained } \\
\text { sample } \\
{[\%]}\end{array}$ & $\begin{array}{c}\text { Waterless } \\
\text { sample } \\
{[\%]}\end{array}$ & $\begin{array}{c}\text { Sample } \\
\text { combustible } \\
{[\%]}\end{array}$ \\
\hline Gross water & 4.08 & - & - \\
Residual water & 7.15 & - & - \\
Water total & 11.23 & - & - \\
Ash content at $550^{\circ} \mathrm{C}$ & 1.02 & 1.15 & - \\
\hline Combustible & 87.75 & 98.85 & 100 \\
Volatile matter & 70.35 & 79.25 & 80.17 \\
Fixed carbon & 17.40 & 19.60 & 19.83 \\
\hline & Ultimate analysis \\
\hline Hydrogen H & 5.65 & 6.36 & 6.43 \\
Carbon C & 42.59 & 47.98 & 48.54 \\
Nitrogen N & 3.64 & 4.10 & 4.15 \\
Oxygen O & 35.84 & 40.37 & 40.84 \\
\hline Sulphur total & 0.04 & 0.05 & - \\
Sulphur volatile & 0.03 & 0.04 & 0.04 \\
Sulphur in ash & 0.10 & 0.01 & - \\
Cl total & - & 0.048 & - \\
\hline
\end{tabular}

Fluorides $284[\mathrm{mg} / \mathrm{kg}]$ in dry matter $[3,4]$ 
Table 2: Energy parameters of the test specimen of "fuel" [4]

\begin{tabular}{|c|c|c|c|}
\hline \multicolumn{4}{|c|}{ Energy parameters } \\
\hline Anneal & $\begin{array}{c}\text { Obtained } \\
\text { sample } \\
{[\%]}\end{array}$ & $\begin{array}{c}\text { Waterless } \\
\text { sample } \\
{[\%]}\end{array}$ & $\begin{array}{c}\text { Sample } \\
\text { combustible } \\
{[\%]}\end{array}$ \\
\hline Combustion heat $[\mathrm{kJ} / \mathrm{kg}]$ & 17601 & 19828 & 20059 \\
Heat value $[\mathrm{kJ} / \mathrm{kg}]$ & 16068 & 18433 & 18647 \\
\hline
\end{tabular}

Table 3: Chemical analysis of ash from crushed furniture $[3,4]$

\begin{tabular}{|lc|lc|}
\hline \multicolumn{4}{|c|}{ Chipboard ash composition } \\
\hline Compound & {$[\%]$} & Element & {$\left[\mathrm{mg} / \mathrm{kg}_{\text {ash }}\right]$} \\
\hline $\mathrm{SiO}_{2}$ & 15.30 & $\mathrm{~Pb}$ & 223 \\
$\mathrm{Fe}_{2} \mathrm{O}_{3}$ & 3.60 & $\mathrm{Cd}$ & less than 10 \\
$\mathrm{MnO}$ & - & $\mathrm{Cu}$ & 484 \\
$\mathrm{Al}_{2} \mathrm{O}_{3}$ & 7.28 & $\mathrm{Hg}$ & less than 10 \\
\hline $\mathrm{TiO}_{2}$ & 25.80 & $\mathrm{Mn}$ & 12500 \\
$\mathrm{CaO}$ & 19.00 & $\mathrm{Cr}$ & 170 \\
$\mathrm{MgO}$ & 4.35 & $\mathrm{Ni}$ & 107 \\
$\mathrm{Na}_{2} \mathrm{O}$ & 1.83 & $\mathrm{Zn}$ & 2900 \\
$\mathrm{~K}_{2} \mathrm{O}$ & 8.90 & $\mathrm{Cl}$ & 0.46 \\
$\mathrm{SO}_{3}$ & 2.77 & & \\
$\mathrm{P}_{2} \mathrm{O}_{5}$ & 2.34 & & \\
\hline
\end{tabular}

\section{Chipboard ash}

The composition of ash has a significant impact on its properties, and consequently also on the ways in which the fuel is utilized in various technologies. This is particularly the case for new untested fuels.

Typical problems are with ash sintering, which is dependent on the composition of the ash. Here, the most important elements are silicon, sodium and potassium, because the oxides of these elements have a big influence on the sintering temperature of the ash. Chemical analyses were made of chipboard ash in order to illustrate fully the effect of ash on the equipment. The analyses were performed in an accredited laboratory. The ash was obtained by controlled annealing of the material at $550{ }^{\circ} \mathrm{C}$. The values of the content of individual constituents are given in the table 3 .

\section{Experimental measurements}

Test measurements were made on the BIOFLUID 100 experimental unit in 2010 and 2011. A more detailed description of our experimental unit can be found in earlier studies published by our institute. The main purpose of the experimental measurement was to establish the potential for thermal gasification of crushed furniture chipboard. As this is not a conventional fuel, the initial measurements aimed mainly at finding and verifying a suitable gasification method for this material. The tests focused on the process of gasification proper of the material, to see whether there are any process limitations. [3]

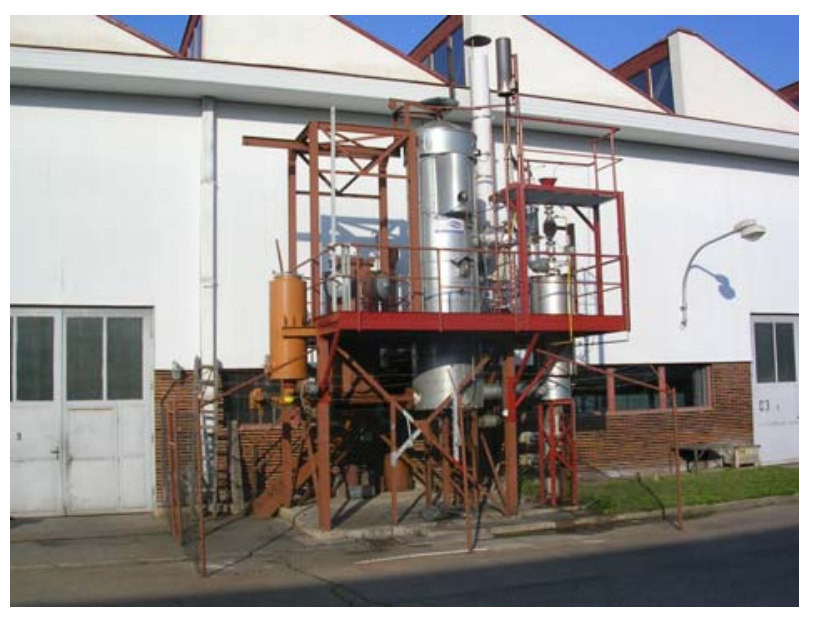

Figure 1: The BIOFLUID 100 experimental gasification unit $[8]$

In the early stage of the first measurements, difficulties arose with stabilization of gasification temperature. These difficulties were successfully resolved in the course of the experiment. The probable cause was the supply of excessive amounts of primary air, and the relatively fine consistency fuel that was probably released from the fluidized bed. In other words, no stable fluidized bed could properly form. Nevertheless, the first experiments showed that chipboard can be gasified using Biofluid. However, it is necessary to take into account the consistency of the fuel, and changes in the control of the screw conveyor must be made gently. 


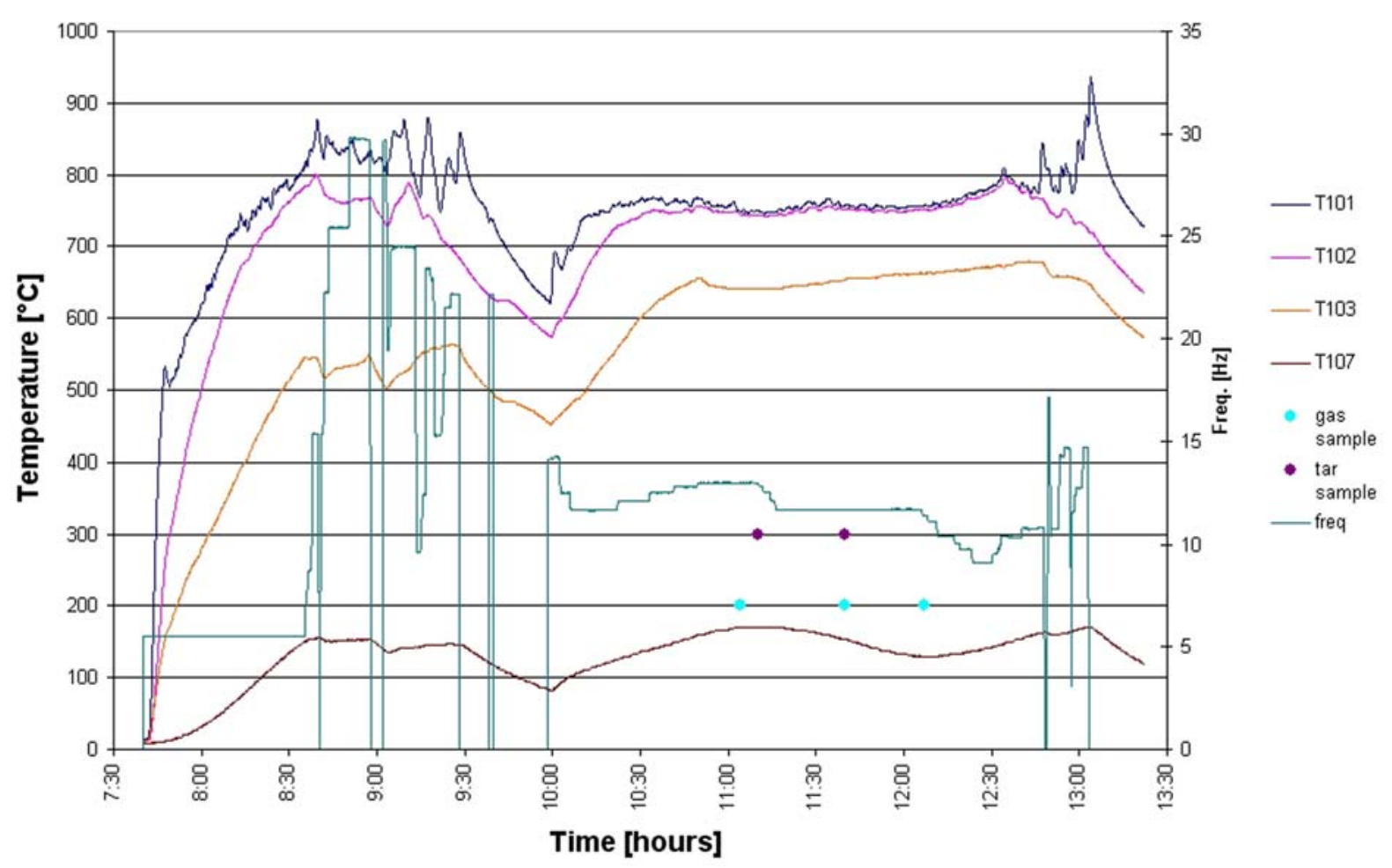

Figure 2: Important temperatures in the gasifier, and an indication of the time course of the gas tar samplings (T101 - temperature on the fire grid, T102 - temperature at the beginning of the fluidized bed, T103 temperature on top of the fluidized bed, T107 - temperature at the outlet from the gasifier)

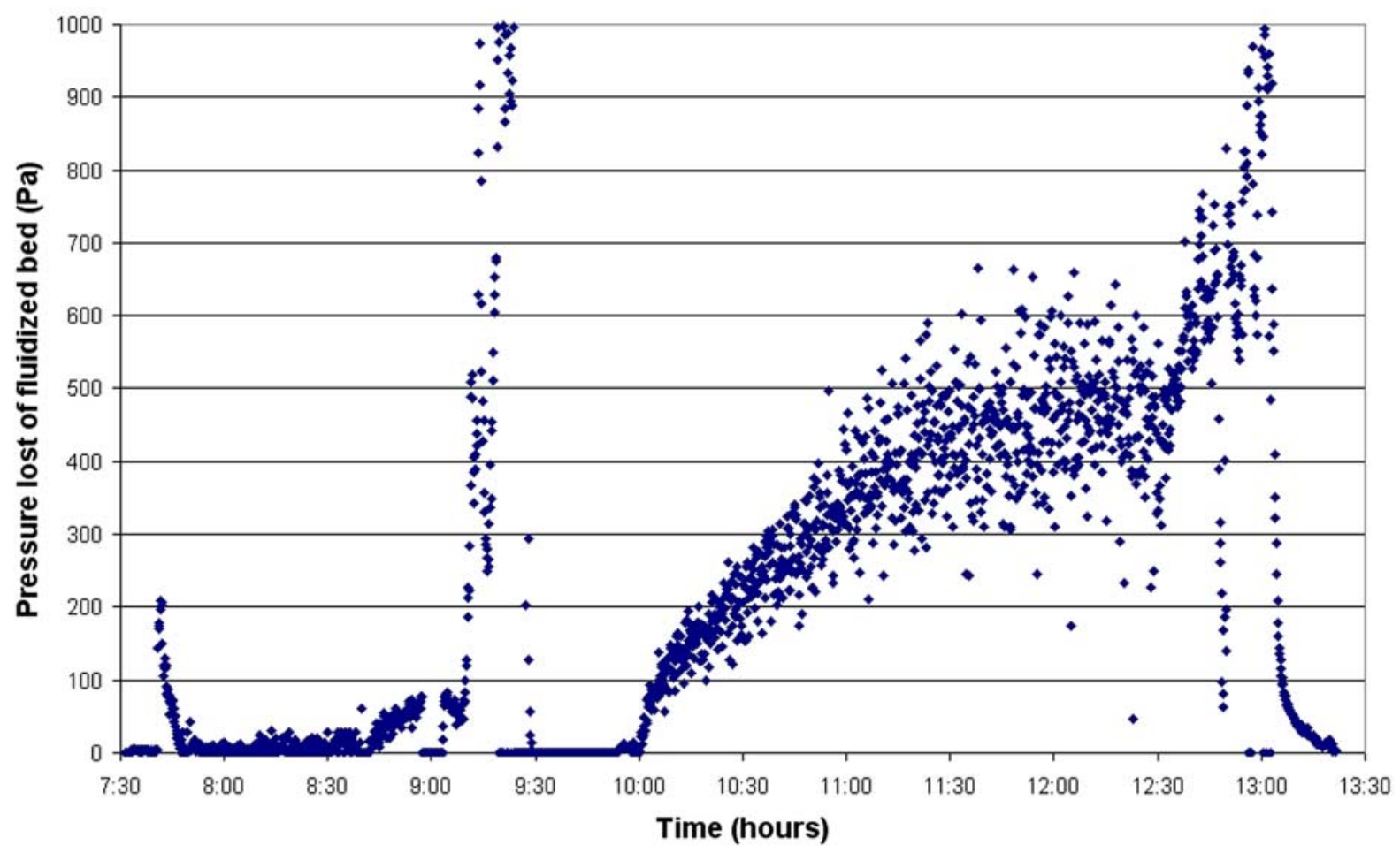

Figure 3: Measurements of the pressure loss of the fluidized bed are used to describe the stability of the fluidized bed and the gasification process 
Table 4: Composition of the gas mixture produced during the experiments

\begin{tabular}{|c|c|c|c|c|c|c|c|c|c|}
\hline $\begin{array}{c}\text { Sample } \\
\text { Time }\end{array}$ & $\begin{array}{c}\text { Temperature } \\
{\left[{ }^{\circ} \mathrm{C}\right]}\end{array}$ & $\begin{array}{c}\mathbf{C O}_{2} \\
{[\%]}\end{array}$ & $\begin{array}{c}\mathbf{H}_{2} \\
{[\%]}\end{array}$ & $\begin{array}{c}\mathbf{C O} \\
{[\%]}\end{array}$ & $\begin{array}{c}\mathbf{C H}_{4} \\
{[\%]}\end{array}$ & $\begin{array}{c}\mathbf{N}_{2} \\
{[\%]}\end{array}$ & $\begin{array}{c}\text { Ethane } \\
{[\%]}\end{array}$ & $\begin{array}{c}\text { Misc } \\
{[\%]}\end{array}$ & $\begin{array}{c}\text { Sum Total } \\
{[\%]}\end{array}$ \\
\hline \multicolumn{7}{|c|}{} \\
\hline $11: 04$ & $\mathbf{7 6 0}$ & 16.80 & 6.38 & 13.33 & 5.07 & 57.81 & 0.480 & 0.130 & 100 \\
$11: 40$ & $\mathbf{7 6 0}$ & 17.39 & 6.54 & 12.19 & 4.14 & 59.28 & 0.350 & 0.110 & 100 \\
$12: 07$ & $\mathbf{7 6 0}$ & 17.58 & 7.25 & 13.79 & 4.15 & 56.83 & 0.280 & 0.110 & 100 \\
\hline \multicolumn{7}{|c|}{} \\
\hline $12: 04$ & $\mathbf{7 8 0}$ & 17.33 & 7.63 & 14.36 & 3.64 & 56.76 & 0.160 & 0.110 & 100 \\
$12: 42$ & $\mathbf{7 7 0}$ & 17.57 & 7.09 & 12.45 & 2.97 & 59.69 & 0.120 & 0.110 & 100 \\
$13: 07$ & $\mathbf{7 8 0}$ & 18.15 & 6.54 & 10.51 & 2.05 & 62.04 & 0.660 & 0.040 & 100 \\
$13: 43$ & $\mathbf{8 0 0}$ & 16.80 & 6.19 & 11.27 & 1.93 & 63.07 & 0.670 & 0.060 & 100 \\
$14: 18$ & $\mathbf{8 0 5}$ & 17.22 & 7.44 & 12.43 & 2.20 & 59.90 & 0.760 & 0.040 & 100 \\
$14: 53$ & $\mathbf{8 0 5}$ & 15.81 & 7.09 & 13.54 & 2.87 & 59.74 & 0.880 & 0.070 & 100 \\
\hline
\end{tabular}

Table 5: Summarized results from tar analysis to for comparison

\begin{tabular}{|c|c|c|}
\hline Gasification temperature & $770^{\circ} \mathrm{C}$ & $800^{\circ} \mathrm{C}$ \\
\hline Volume of gas [1] & 156.0 & $\overline{156.0}$ \\
\hline Volume of acetone $[\mathrm{ml}]$ & 156.3 & 161.8 \\
\hline Benzene $\left[\mathrm{mg} / \mathrm{m}^{3}\right]$ & 3453.7 & 3645.5 \\
\hline Toluene $\left[\mathrm{mg} / \mathrm{m}^{3}\right]$ & 1619.0 & 1413.3 \\
\hline $\mathrm{m}+\mathrm{p}+\mathrm{o}$-xylen + ethylbenzene + phenylethyne $\left[\mathrm{mg} / \mathrm{m}^{3}\right]$ & 603.4 & 954.3 \\
\hline Styrene $\left[\mathrm{mg} / \mathrm{m}^{3}\right]$ & 725.0 & 627.1 \\
\hline C3-benzene sum $\left[\mathrm{mg} / \mathrm{m}^{3}\right]$ & 1013.3 & 847.3 \\
\hline BTX sum $\left[\mathrm{mg} / \mathrm{m}^{3}\right]$ & 7414.4 & 7487.6 \\
\hline Oxygenous sum $\left[\mathrm{mg} / \mathrm{m}^{3}\right]$ & 2854.2 & 1353.6 \\
\hline other substances $(\operatorname{tar})\left[\mathrm{mg} / \mathrm{m}^{3}\right]$ & 398.4 & 452.0 \\
\hline sum of TAR (wihtout BTX) $\left[\mathrm{mg} / \mathrm{m}^{3}\right]$ & 5779 & 4730 \\
\hline tar by TAR protocol $\left[\mathrm{mg} / \mathrm{m}^{3}\right]$ & 9740 & 8572 \\
\hline
\end{tabular}

To form an idea, the following graph shows the temperature course of one of the experiments in relation to the frequency values of the screw conveyor. It is clear that the initially unstable course of gasification was successfully stabilized. It was only after an attendant's intervention in the screw conveyor frequency that temperature fluctuations occurred in the gasifier.

Another measured variable is the pressure loss of the fluidized bed. A change in this value shows the stability of gasification process during the experiment.

The next task was to conduct chipboard gasification at temperatures ranging from $760^{\circ} \mathrm{C}$ to $830^{\circ} \mathrm{C}$, and to assess the impact of the gasification temperature on the composition of the resultant gas. After the unit had been heated to the required op- erating temperature, samples of tar and gas were taken. The following table summarizes the volume concentration values of individual constituents of the produced gas mixture. The samples are indicative of the production of a relatively stable mixture of gases.

It was found that the gas composition values and the tar content values in relation to temperature correspond with the tar content in the gasification of conventional wood chips. However, deposits of compounds that have not yet been closely examined were left on the walls of the sample containers following the sampling. The next table summarizes some of the tar analysis results for the purposes of comparison. Only a small part of the total tar analysis is shown, as a single analysis produces a large number of values. 


\section{Conclusions}

The results of our experiments have shown that it is feasible to gasify crushed chipboard. What is important, however, is stepwise and unhurried control of the screw conveyor operation to avoid clogging. It was also noted that the temperature response of chipboard to the screw conveyor frequency is much slower than in the case of fuel wood chips.

The fluctuational pressure loss of the fluidized bed testifies to poorer stability of the proper gasification process. The fluctuations may originate from a lack of homogeneity of the tested fuel. The crushed furniture contained a relatively high volume of fine fraction, which sank to the bottom of the feedstock container during handling, and was therefore the first to enter the gasifier.

The experiments show that the optimum temperature for chipboard gasification is somewhere around $800^{\circ} \mathrm{C}$. In gasification at temperatures in excess of $820^{\circ} \mathrm{C}$, fuel caking occurs in the fluidized bed, and it also solidifies above the grate. At temperatures below $770^{\circ} \mathrm{C}$, there is a growing tar content in the gas that is produced.

A comparatively high concentration of undesirable compounds that are harmful to health was assumed, due to the high content of additives used in chipboard manufacture. However, the gas that is produced is just an intermediary of this technology. The resultant concentrations of harmful substances should only be quantified after the gas has been combusted. To carry on with this research, BIOFLUID has been equipped with a special combustion chamber, in which the gas will be used as a fuel. In the course of the follow-up research, emission measurements will be carried out only with the outlet flue gas.

\section{Acknowledgement}

This research was realized with support from the Faculty of Mechanical Engineering, Brno University of Technology, in project FSI-J-10-40 Thermal Liquidation of Contaminated Biomass.

\section{References}

[1] Baláš, M., Lisý, M.: Water-steam influence on biomass gasification process, Acta Metallurgica Slovaca, 11, 1, 2005, 14-21, (in Czech). ISSN 1335-1532.

[2] Werthera, J., Saengera, M., Hartgea, E.-U., Ogadab, T.: Combustion of agricultural residues, Progress in Energy and Combustion Science, 26, PERGAMON, 2000, 1-27.

[3] Moskalík, J., Škvařil, J., Štelcl, O., Baláš, M., Lisý, M.: ENERGY USAGE OF CONTAMINATED BIOMASS, Acta Metallurgica Slovaca Conference, Vol. 2, No. 1, 2011, p. 145-151. ISSN 1338-1660.

[4] Kotlánová, A.: Research paper of fuel testing sample of fuel, Testing laboratory, TÜV NORD Czech, 2010.

[5] Tame, N. W., Dlugogorski, B. Z., Kennedy, E. M.: Formation of dioxins and furans during combustion of treated wood:, Elsevier Science, Progress in Energy and Combustion Science, 33, 2007, 384-408.

[6] Vamvuka, D., Karouki, E., Sfakiotakis, S.: Gasification of waste biomass chars by carbon dioxide via thermogravimetry. Part I: Effect of mineral matter, FUEL, ELSEVIER Science, 2010.

[7] Schtowitz, B., Brandt, G., Grafner, F., Schlumpf, E.: Dioxin emissions from wood combustion, Chemosphere, vol. 29, Elsevier Science, 1994, 2005-2013.

[8] Baláš, M., Lisý, M., Kohout, P., Ochrana, L., Skoblia, S.: Nickel catalysts gas cleaning, Acta Metallurgica Slovaca, 13, 3, 2007, 18-26, (in Czech). ISSN 1335-1532. 